\title{
Os portugueses e a colonização do Brasil na Revue des DeuxMondes: mensageiros da civilização ou males de nossa terra?
}

The Portuguese and the colonization of Brazil in the Revue des Deux Mondes: messengers of civilization or evils of our land?

Los portugueses y la colonización de Brasil en la Revue des DeuxMondes: ¿mensajeros de la civilización o los males de nuestra tierra?

\section{Resumo}

Este artigo tem como objetivo compreender as representações sobre os portugueses e a colonização que empreenderam no Brasil, nas publicações da Revue des Deux Mondes do século XIX. A partir da leitura dos artigos publicados sobre o Brasil desse período, buscaremos compreender como os viajantes franceses enxergavam os portugueses, tendo como objeto principal de análise as relações entre os climas e a formação dos povos, importantes elementos explicativos dentro das concepções do século XIX, e como isso se refletiu na colonização do Brasil que encontraram.

Palavras-chave: Colonização Portuguesa. Diálogos Transnacionais. História Cultural. Relatos de Viajantes. Revue des Deux Mondes.
A Revue des Deux Mondes foi um periódico francês do século XIX, que nasceu com um objetivo: buscar o outro, a fim de conhecê-lo e, assim, levar para a França aquilo que de melhor havia nos mais diversos povos e países espalhados pelo globo, contribuindo, assim, para uma melhor organização e um melhor desenvolvimento da própria sociedade francesa (BARBATO, 2015, p. 17).

E o contato com esse mundo distinto que se apresentava para ser desvendado e conhecido se daria através dos viajantes, que

\footnotetext{
Doutor em História pela Universidade Estadual de Campinas, Brasil. Professor do Instituto Federal do Triângulo Mineiro, Brasil. E-mail: lfbarbato@ gmail.com
}

Recebido em 09/04/2016 - Aprovado em 10/10/2016 http://dx.doi.org/10.5335/hdtv.17n.1.6030 
sairiam da França dispostos a reparar em tudo e a registrar aquilo que melhor atendesse aos objetivos traçados pelos editores da Revue. Dessa maneira, o Brasil tornou-se o objeto central de alguns dos escritos que figuraram no periódico francês oitocentista, nos quais sua sociedade sui generis, marcada por exotismos e problemas, foi descrita e pensada pelos viajantes franceses.

Nesses escritos, os mais diversos fatores e as mais diversas características são descritos e analisados sob o viés de homens vindos de um considerado centro cultural e imersos nas ideias próprias do século XIX, como a crença no progresso e no poder da ciência, como eram as concepções dos viajantes da Revue. Os portugueses e a colonização que empreenderam no Brasil foram alvos de polêmica, afinal, seriam eles alguns dos principais responsáveis pela sociedade imperfeita e ainda à beira da civilização que os viajantes encontraram no país americano.

Pretendemos aqui analisar como os portugueses, enquanto membros constituintes da sociedade brasileira, foram tratados na Revue des Deux Mondes, buscando, principalmente, associar a análise dos franceses a um dos pressupostos mais importantes do século XIX: a questão mesológica na formação dos povos. Tal questão é pertinente, porque a associação entre meio e sociedade foi marcante no século XIX e utilizada como forma de explicar deficiências e inferioridades que ajudavam a dar sentido a esse mundo oitocentista.

Desde tempos muito remotos ${ }^{1}$, os trópicos eram vistos como lugares avessos à civilização que a Europa produzira. Vale ressaltar que, quando falamos de trópicos, estamos tratando-os mais como uma cons- trução discursiva, marcada por características não inerentes ao antagônico clima temperado europeu, como o calor perene, a umidade excessiva e uma natureza exuberante e benevolente com seus viventes, que de uma delimitação geográfica.

Um dos motivos das vivas de Sérgio Buarque de Holanda aos portugueses, presentes em obras como Raízes do Brasil ou A Visão do Paraíso, foi justamente a sua habilidade de se trasladar às zonas tórridas e de habitá-las, desafiando o conceito quinhentista de que os homens nela degeneravam-se, $\mathrm{o}$ que mostra que há tempos essa relação dicotômica entre trópicos e civilização possuía força no pensamento social europeu.

Mas essas concepções já estavam arraigadas há tempos nas mentalidades europeias, desde o século XVIII elas começaram a ser tratadas de maneira mais sistemática, sendo objeto de reflexões de grandes nomes das letras, da filosofia e das ciências europeias. Nesse sentido, as palavras de Roberto Ventura, citando Montesquieu e Buffon, apresentadas a seguir, mostram-nos a força que essa relação ganhou nos idos dos setecentos:

[...] não surpreende que a covardia dos povos dos climas quentes os tenha tornado quase sempre escravos, e que, a coragem dos povos dos climas frios os tenha mantido livres. É um efeito que deriva de sua causa natural (MONTESQUIEU, 1983 apud VENTURA, 1991, p. 20).

O clima temperado se localiza do $40^{\circ}$ a $50^{\circ}$ grau de latitude; é também nessa zona que se encontram os homens mais belos e bem feitos (...) é daí que se devem tomar o modelo e a unidade a que se devem referir todas as outras nuances de cor e beleza (BUFFON, 1987 apud VENTURA, 1991, p. 21-22). 
Não pretendemos nos alongar nesse assunto $^{2}$, mas, além de Buffon e Montesquieu, diversos outros europeus dedicaram-se a ressaltar as inferioridades dos homens nascidos sob os trópicos em relação àqueles forjados nas durezas do clima temperado europeu. Como observa Glacken, em nenhuma das épocas anteriores, os pensadores se haviam posto a examinar as questões relativas à cultura e ao ambiente com tanta minúcia, curiosidade e dedicação como fizeram no século XVIII (GLACKEN, 1967, p. 501).

O século XIX herdou essas ideias que se fortaleceram no século anterior, e a questão mesológica, que propagava as diferenças e ressaltava as inferioridades entre esses dois polos distintos que eram Europa e trópicos (BARBATO, 2014, p. 175-186), continuaram a ganhar força ${ }^{3}$, tanto que ela guiou nossa análise das representações dos portugueses e de seu processo colonial no Brasil, nos relatos de viagem da Revue de Deux Mondes.

No entanto, esses europeus, vindos de uma Europa Ibérica mais quente em seu clima e em suas paixões, não deixavam de mostrar suas debilidades diante daqueles outros europeus, vindos de terras para além dos Pirineus, sujeitas a rigores que os peninsulares pouco conheciam, benesses essas que acarretariam fraquezas sentidas naquele "mundo que o português criou" (FREYRE, 1940) e que não passariam incólumes aos olhares atentos de olhos dispostos a, em tudo, reparar.

Eles eram europeus, sua posição geográfica no ocidente do continente e a civilização que trouxeram, mesmo com suas falhas, não permitiam que se afirmasse $o$ contrário. Mas, comparados a seus conterrâ- neos do norte, tinham muitas falhas, eram os fracos entre os fortes:

Cette répugnance au travail, cette insouciance philosophique que les conquistadores ont toujours professée à l'endroit du comfort, ne peuvent être attribuées à un manque d'énergie, car aucun peuple que je sache n'a déployé dans l'histoire du monde une plus grande somme d'audace et de mâle activité que cette tribu celtibérienne resserrée entre les montagnes et l'Océan. Après avoir refoulé l'islamisme, se sentant à l'étroit dans sa langue de terre, elle affronta la première les redoutables mystères d'une mer inconnue et sans limites, explora les côtes d'Afrique, franchit le Cap des Tempêtes, fraya la grande route des Indes et peupla l'Asie de ses comptoirs, tandis que, d'un autre côté, Cabrai, poussant vers l'ouest, rencontrait ce continent que Colomb avait cherché en vain. Ce fut encore un Portugais, Magellan, qui, bravant les rigueurs du pôle sud, entra dans le Pacifique par une route nouvelle, et procura à ses compagnons la gloire de sillonner dans toute leur circonférence ce globe et cet océan, jusqu'alors fermés à la science et à l'investigation humaines. De tels hommes ne pouvaient comprendre l'esprit nouveau. Écoutez leur idiome si riche, si sonore, si passionné pour chanter les exploits des héros ou les cantiques des saints : il devient muet quand vous lui demandez un traité scientifique ou un livre de pratique industrielle. C'est une langue de paladins et non d'artisans. Telle langue, telle nation. Héritiers du monde romain et dernière personnification du moyen âge, ces hommes d'épée ne voyaient dans le travail que l'apanage des serfs. Toute innovation qui touchait à une telle base devait être un crime. À la réforme ils répondirent par l'inquisition. Pendant que les races anglo-saxonnes ouvraient l'oreille à la grande voix de Luther, ils se mettaient sous le patronage de Dominique et de Loyola. Les deux symboles ont porté leurs fruits (D’ASSIER, 1863, p. 97-98)4. 
O trecho acima nos dá uma clara mostra da visão que os portugueses partilhavam entre as potências da Europa oitocentista. Era um povo louvável, detentor de grande orgulho histórico, capaz de feitos únicos no mundo, como conduzir com tamanha maestria a colonização extensiva de zonas tão distintas daquelas às quais estava acostumado, como os trópicos, mas que havia parado no tempo e não acompanhado a evolução que germânicos, ingleses, ou mesmo franceses, alcançaram. Mais preocupados em enriquecer inconsequentemente e em construir igrejas no lugar de escolas ${ }^{5}$, os portugueses deixaram sua contribuição para o estado das coisas que os olhos franceses encontraram na antiga colônia lusitana, agora aberta à visitação ${ }^{6}$.

Eram eles, afinal, um povo europeu localizado já às margens da Europa, sujeitos ao calor vindo da África e ao frio, da Europa, uma "ponte", como nos trouxe Gilberto Freyre, entre a Europa do progresso e a África do atraso. Eram um povo de tez escurecida pelo contato com os mouros (MONTEIRO, 1999, p. 91) e com os negros africanos; aventureiros preocupados somente em usufruir da terra e amantes do ganho fácil, na análise de Sérgio Buarque de Holanda (1984, p. 13-24); e preguiçosos e dados aos prazeres da carne, na visão de Paulo Prado (1998 apud KEULLER, 2001, p. 186). Essas visões, se comparadas aos relatos que sobre os portugueses produziram outros europeus, encontram amparo, conforme mostram as publicações da Revue.

Dessa maneira, os portugueses, europeus já relativamente tropicalizados desde a sua origem, poderiam dar prosseguimento à missão civilizatória tão extensa que lhes cabia? Com base nos relatos publicados na Revue, podemos notar que a eles eram dados louros, mas as críticas à civilização frouxa que deixaram e aos seus modos perdulários de colonizar também eram persistentes.

Esses louros à presença lusitana nos trópicos já foram fartamente descritos pela historiografia e devem-se, principalmente, a um pródigo passado lusitano. Nesse sentido, Sérgio Buarque de Holanda nos informa que nenhum outro povo do Velho Mundo mostrou-se tão apto a se aventurar na exploração regular e intensa de terras tão distintas das europeias como o povo português, justamente por estarem essas terras próximas à linha equinocial, onde os homens degeneravam, segundo o conceito quinhentista. As próprias palavras do autor deixam evidentes essas glórias: "pioneiros da conquista do trópico para a civilização, tiveram os portugueses, nessa proeza, sua maior missão histórica" (HOLANDA, 1984, p. 12).

O próprio Gilberto Freyre, que viu no português e em sua abertura natural para o contato com negras e índias o embrião de um Brasil todo especial, é outro que exalta nosso colonizador lusitano, colocando-o na base da "malemolência" brasileira e dando àquele Brasil mestiço e tropical um futuro positivo $^{7}$, nunca antes pensando ${ }^{8}$ em tempos dominados por inferioridades climáticas e raciais (BARBATO, 2010, p. 58).

Mas essa capacidade incrível de se trasladar de uma zona à outra da Terra, mesmo que separadas por oceanos, distantes e desafiadoras, mantendo ainda o ímpeto e a energia necessários à colonização - algo que somente os portugueses pareciam ter em grau necessário para colonizar um país de 
dimensões continentais feito o Brasil -, não carecia de problemas. Segundo Holanda - o mesmo que enaltece tal capacidade lusitana -, apesar da energia empregada na empreitada-Brasil, a ação portuguesa não contou com um processo metódico e racional; pelo contrário, foi realizada sob o prisma do abandono e do desleixo, faltando vontade construtora e energia - que sobravam ao se lançarem ao desconhecido - que estavam além da vontade de explorar.

Nesse sentido, para mostrar o desmazelo português em seu projeto - se é que existiu um projeto - de colonização no Brasil, Holanda traz a metáfora da dicotomia entre o aventureiro e o trabalhador, sendo o primeiro marcado pelo ideal de "colher o fruto sem plantar a árvore", ao passo que o segundo "enxerga primeiro a dificuldade de vencer, não o triunfo a alcançar" ". Ávidos por lucros fáceis, tanto na agricultura como nas atividades comerciais, os portugueses, dentro da dicotomia de Holanda, aparecem como aventureiros.

Essa visão pouco alentadora acerca dos lusitanos pode ser observada nas críticas feitas ao modo com que eles praticavam a agricultura nas suas terras coloniais brasileiras, segundo Buarque de Holanda, "de natureza tão perdulária quanto a mineração" (HOLANDA, 1984, p. 19). O mesmo se dava na vida urbana, na qual, segundo o historiador, "reinava o mesmo amor ao ganho fácil e a infixidez que tanto caracterizaram, no Brasil, os trabalhos rurais" (HOLANDA, 1984, p. 18).

Dessa maneira, as mazelas do Brasil não tinham outro culpado, segundo o autor, não tinham outra origem. Se quisessem encontrar os responsáveis por elas, seriam os portu- gueses, já que, segundo Edgar de Decca, apesar da presença de negros e índios na nossa história, Sérgio Buarque de Holanda atribui toda a responsabilidade da construção do Brasil que conhecemos ao português, que da Europa partiu e nestas terras distantes e distintas se instalou. Assim, seria impossível, e até injusto, apregoar uma igualdade de responsabilidades entre as três raças no que toca à formação do Brasil. Segundo Sérgio Buarque de Holanda, todas as formas de exclusão e de violência, muito bem dissimuladas nos traços cordiais presentes no brasileiro de seu tempo, eram em razão da colonização portuguesa (DECCA, 2002, p. 11-12).

Dentro de um contexto como esse, ocupam o centro europeu, mas a meio caminho da África, sujeitos às glórias da civilização que sopram do norte em ventos frios e às mazelas da barbárie que sopram do sul em ventos quentes. Será que podemos relacionar as dificuldades que a civilização brasileira enfrentava à época das visitas dos escritores que estudamos, iniciadas e comandadas pelos portugueses, ao problema climático? Tal resposta é algo difícil de ser encontrado, pelo menos de uma maneira precisa, pois isso não se mostra de forma direta nos escritos da Revue. A verdade, no entanto, é que, mesmo se tratando de europeus falando de europeus, podemos notar que a questão climática dá suas caras, ainda que de maneira tímida e sutil.

O clima mais ameno da Península Ibérica ajudou o português - e também o espanhol - a ter êxitos incríveis no Novo Mundo. Os dizeres seguintes mostram que, sobre os portugueses, pairava essa noção de serem mais propensos a colonizar os trópicos que europeus vindos de latitudes maiores: 
Les paysans de race blanche établis à Cuba et à Porto-Rico, les islingues ou isleños, qui travaillent la terre dans les Antilles et en diverses parties du continent américain, prouvent d'une manière incontestable, par leur exemple et une prospérité relative, que certains blancs peuvent aussi bien que les noirs cultiver le sol des contrées tropicales ; mais ces blancs acclimatés sont originaires de l'Espagne, du Portugal, de Madère, des Açores, des Canaries, et le soleil brûlant de leur pays natal les avait déjà préparés à la température de la zone torride. Probablement aussi des colons venus d'Allemagne, $d^{\prime}$ Irlande et d'autres contrées du nord de l'Europe pourraient-ils, sans danger pour leur santé, s'adonner à l'agriculture dans le Brésil équatorial et dans les Guyanes, à la condition d'observer une sobriété rigoureuse, de changer complètement leur genre de vie et de prendre des précautions auxquelles ils n'ont jamais été habitués ; mais on ne saurait demander une si profonde science de l'hygiène à des hommes que la misère, exile de leur patrie, et qui, peu de temps avant leur départ, ignoraient peut-être encore s'ils devaient choisir pour leur nouvelle demeure les bords glacés du Saint-Laurent ou les moites forêts de l'Amazone (RECLUS, 1862, p. 954) ${ }^{10}$.

Nesse sentido, segundo consta na revista, os mais amenos climas também ajudaram a construir um gênio menos ativo que os encontrados nas frias terras do norte da Europa. Lá, em meio a invernos realmente rigorosos, formavam-se os fortes, e os portugueses já se mostravam um pouco amolecidos pelos prazeres do clima ibérico, o que mostra que as noções anteriores, que tropicalizam e, assim, inferiorizam os portugueses, pelo menos fazem sentido. Dessa forma, seu gênio pode ser comparado ao do brasileiro, mais espirituoso, porém, também, mais dado ao vício, como encontramos na comparação seguinte, de Saint-Hilaire: “Les
Portugais et les Brésiliens sont des peuples spirituels, mais peu instruits et inoccupés; par l'intrigue, ils exercent leur esprit et font prendre le change à leur oisiveté" (SAINT-HILAIRE, 1831, p. 345) ${ }^{11}$.

Assim, povos de locais menos frios e, por consequência, povos menos apegados à sisudez e às responsabilidades, como os lusitanos, relativamente tropicalizados em análises comparativas a outros europeus, dão brechas para que os franceses apontem suas fraquezas e as consequências disso naquele Brasil problemático que encontraram. Assim, se, entre as críticas aos lusitanos que aparecem na Revue, aquelas eram indiretas - simplesmente por comparar seus espíritos aos débeis espíritos tropicais e mestiços brasileiros -, algumas surgem de maneira mais clara, criticando sua inata inaptidão à ciência e ao trabalho, em oposição a um vigor direcionado para a exploração, como podemos encontrar nas palavras de Assier:

Les causes remontent plus haut: elles ont leur source dans ce dur génie portugais, mélange de fatalisme arabe et d'âpreté ibérique propre à l'épopée, mais rebelle à la science et au travail. Dès que la première fièvre de l'occupation fut apaisée, les conquistadores ne songèrent plus qu'à jouir en paix de la terre promise. Leurs descendans allèrent plus loin : quittant le casque de leurs rudes ancêtres pour le sombrero du planteur et leur vaillante épée pour le fouet du feitor, ils s'enveloppèrent dans leur manteau d'hidalgos, et laissèrent aux tribus vaincues le soin de les enrichir. Dédaignant les lentes productions de la terre, si féconde pourtant sous les tropiques, ils ne voulurent que de l'or. Pour en retirer quelques lingots, ils ont brûlé les forêts, bouleversé le sol, exterminé les peuplades indiennes et condamné à l'esclavage plusieurs millions de noirs (D'ASSIER, 1863, p. 96) ${ }^{12}$ 
Tal noção, no entanto, ainda não está clara, não é aberta. Entretanto, com base nas entrelinhas do discurso, podemos enxergar uma aproximação feita pelos franceses dos portugueses aos trópicos, muito mais que qualquer outro povo da Europa - exceção feita talvez aos seus vizinhos ibéricos espanhóis -, colocando-os como partilhantes dos mesmos problemas, originados em um clima quente, e de mesmas questões inferiorizantes, guardadas as devidas proporções. Isso, é claro, se dá em um contexto de comparação de Europa com Europa pelos escritores da Revue, pois, em um contexto de comparação entre Europa e Novo Mundo, os portugueses eram enaltecidos; e, se havia nestas terras um estado que, mesmo lentamente, progredia, isso era essencialmente devido à semente de civilização, plantada pelos portugueses.

Dessa maneira, apesar de serem, aos olhos dos viajantes franceses, europeus "afrouxados" e amolecidos pelo clima mais ameno, se comparados ao restante da Europa, ainda eram europeus e ainda representavam o progresso e a civilização nessas terras distintas e indômitas. Nesse sentido, ressalta-se que, apesar das críticas que recebeu, principalmente em relação à má administração que exerceu no Brasil, esse povo mediterrânico foi alvo de muitos vivas na Revue, que mostram claramente o progresso do Brasil atrelado à presença europeia, fosse ela do norte ou do sul, como podemos ver nos exemplos seguintes de Théodore Lacordaire:

Ils ne furent pas toujours les agresseurs [como no caso dos espanhóis] dans leurs guerres avec les indigènes, et ils n'eussent pas demandé mieux que de les civiliser. Les Martim Affonso de Souza, les Mendez de Sà, les Albuquerque, les Coutinho, sont des hommes dont le nom est passé avec honneur jusqu'à nous (LACORDAIRE, 1835, p. 336) ${ }^{13}$.

$\mathrm{Ou}$, ainda, em outro exemplo do próprio Lacordaire, em que associa a mudança de uma vida miserável, por parte dos indígenas, para algo melhor, proporcionado pela civilização, que chega junto com a religião difundida pelos jesuítas: "Cependant, sous ces misérables cabanes, le luxe de la civilisation s'était glissé en même temps que la religion" (LARCORDAIRE, 1835, p. 339) ${ }^{14}$.

Além do mais, a casa de Bragança, com origens na Europa, ainda era respeitada. Se o Brasil trilhava caminhos rumo ao progresso, isso ocorria graças àqueles portugueses imigrados que trouxeram consigo a centelha da civilização:

Le Brésil a célébré, le 7 septembre 1872, le cinquantième anniversaire de son indépendance. La dynastie, tige de l'antique maison de Bragance, a jeté dans le sol brésilien des racines profondes. La constitution, fondée sur la souveraineté et la représentation nationale, fonctionne d'une manière régulière; les chambres discutent librement; les partis, qui d'ailleurs sont fidèles aux institutions et à la dynastie, s'agitent avec animation, avec acharnement parfois, mais sans jamais sortir des bornes de la légalité. Cette stabilité politique est la principale cause des progrès du Brésil. Cet immense pays, qui représente à lui seul plus des deux cinquièmes du continent de l'Amérique du Sud, renferme des richesses naturelles dont l'exploitation est à peine commencée (SAINT-ARMAND, 1873, p. 365)..$^{15}$

Em mesmo sentido, Chavagnes aponta que a civilização portuguesa, claramente inserida na Europa, era superior às demais 
que encontrara na formação do Brasil, evidenciando, mais uma vez, que, mesmo em meio às críticas veladas, Portugal ainda era Europa, ainda era forte, e, na cultura por seus homens trazida, o Brasil deveria se firmar:

L'intelligente activité des mulâtres devrait provoquer l'émulation de la société d'origine portugaise et européenne. Il n'en est rien. Cette société voit la supériorité morale lui échapper sans tenter aucun effort pour la ressaisir (CHAVAGNES, 1844, p. 93). ${ }^{16}$

Os portugueses, portanto, deixaram suas marcas negativas no Brasil, que não passaram despercebidas aos olhos franceses da Revue des Deux Mondes. Mas, ao analisarmos essas publicações, podemos observar que, dentre os males, eles eram o menor, visto que eram os representantes da Europa, da terra da civilização nesses trópicos, tanto que o Instituto Histórico e Geográfico Brasileiro, principal agente da construção de uma identidade nacional para o Brasil nos tempos do Império, via a nova nação como continuadora da missão civilizatória iniciada pelos portugueses (GUIMARÃES, 1988, p. 6-8). Assim, ao tratarmos de gentes fracas, incapazes de fazer frente a uma natureza selvagem e vigorosa como a brasileira, os indígenas, os negros e os mestiços desempenhavam o papel decisivo na explicação dos fracassos brasileiros, cabendo aos europeus, por mais que fossem de locais quentes da Europa, as glórias.

Dessa maneira, percebemos, a partir dos relatos presentes na Revue, que muitas das representações que ganharam a historiografia - com destaque para os dizeres de Sér- gio Buarque de Holanda e de Paulo Prado, como aqui notamos, que caracterizavam os portugueses como alguns dos responsáveis por certos fracassos do Brasil -, também se fazem presentes no século XIX, afinal, se eles foram considerados exploradores e perdulários no século XX, no século XIX também o eram, mas de uma maneira muito mais sutil, muito mais matizada.

Afinal, estávamos em um tempo no qual se falava de civilização, em um contexto no qual os povos progrediam em uma linha que invariavelmente daria em um mesmo lugar, e em um momento no qual critérios objetivos são elencados para classificar esses povos, colocando aqueles que têm a aprender em relação com aqueles que têm a ensinar. Nesse contexto oitocentista, em um país marcado por negros e indígenas, inferiores quando o assunto era civilização, esses lusitanos não podiam ser objetos de críticas deveras duras, pois, se havia algo além do natural a ser ressaltado, se havia esperança em um futuro, era devido àqueles ibéricos amolecidos - o que percebemos, pouco importava - que deixaram a Europa e se enfiaram nestas matas densas, lotadas de perigos. Esses eventos não passaram batidos nos escritos da Revue.

Portanto, notamos que, se no século XX os portugueses foram criticados pela sua colonização, no século XIX, mesmo quando comparados a outros europeus, mais inseridos na nova ordem industrial que se projetava, eles ganharam louros. Isso ressalta que, se o Brasil buscava alguém para continuar uma missão iniciada há tantos séculos, era deles o exemplo que se deveria seguir, pois aquele mundo imperfeito que trouxeram 
ainda era o que de melhor o Brasil tinha a oferecer aos olhos franceses, bastando apenas buscar uma atualização e centrando o foco daquele momento em uma era mais moderna.

Pelo que observamos nos relatos sobre os lusitanos da Revue des Deux Mondes, pelo menos a semente os portugueses tinham plantado, o que poderia ser mais bem observado naqueles espaços do Brasil nos quais a civilização, mesmo que imperfeita, dava as suas caras, como era o caso de certas cidades do litoral ou das regiões mais ao sul do país. Como dissemos, embora pudesse ser uma civilização ainda em gestação, imperfeita, ela já se manifestava, mesmo em meio a um Brasil basicamente natural e primitivo; e, se os franceses do século XIX puderam encontrar esses exemplos, foi graças às iniciativas lusitanas.

Ao colocar nos homens as responsabilidades sobre os sucessos e os fracassos da nação, caímos em uma zona na qual o clima tropical surge em sua maneira mais nefasta, e seus efeitos são mais profundos e duradouros: a questão racial. Raça e clima andam juntos no momento de buscar culpados pelos fracassos: se o Brasil era habitado por gentes débeis, incapazes de levar sozinhas um processo civilizacional sem a tutela europeia, era porque indígenas e negros foram forjados sob a égide do sol forte da África e da América, que os brindou com confortos e despreocupações, como nos revelam os relatos oitocentistas. Se mesmo um calor ibérico, com época determinada de duração, já era capaz de amolecer os brios e de minar as energias, como observamos, quais seriam os resultados nos povos nascidos e criados em regiões tropicais, como os índios e os negros, onde a civilização forçava a entrada, como era o caso do Brasil?

Sobre os negros e os indígenas, as críticas eram muito mais diretas, afinal, eles não tinham uma origem que lhes remetesse a civilização, como era o caso dos portugueses, vindos da Europa. Aos negros, aos índios e aos mestiços eram depositadas muitas das explicações dos fracassos que os viajantes franceses encontraram nas terras brasileiras visitadas, contribuindo, em muito, para atenuar as críticas à colonização lusitana no Brasil (BARBATO, 2015, p. 123-159).

Podemos concluir que os portugueses foram alvos de muitas críticas na Revue des Deux Mondes oitocentista, graças à colonização que empreenderam no Brasil, frouxa e débil em muitos sentidos, e explicada, em parte, pela falta de energia que o clima ibérico, já suave demais se comparado ao clima dos países localizados no norte da Europa, provocava em suas gentes.

No entanto, mesmo em meio a críticas, podemos notar que aos mesmos portugueses também são direcionados elogios pelo fato de terem introduzido, mesmo que de maneira ainda superficial, a civilização europeia no Brasil. Dessa forma, os viajantes franceses compreendem o contexto brasileiro, o que ressalta o poder do eurocentrismo da época, uma vez que, mesmo em meio a uma série de críticas, os portugueses se destacam, principalmente por estarem sendo comparados a negros, indígenas e mestiços, considerados os verdadeiros frutos da debilidade tropical. 


\section{Abstract}

This article aims to understand the representations of the Portuguese and colonization that have undertaken in Brazil, within the Revue des Deux Mondes publications of the nineteenth century. From reading the articles published about Brazil that period, we will seek to understand how the French travelers saw the Portuguese, the main object of analysis the relationship between climate and the formation of people, important explicative elements within the concepts of the nineteenth century.

Keywords: Cultural History. Portuguese colonization. Reports of travelers. Revue des Deux Mondes. Transnational Dialogues.

\section{Resumen}

Este artículo tiene como objetivo comprender las representaciones de los portugueses y de la colonización que han llevado a cabo en Brasil en las publicaciones de la Revue de Deux Mondes del siglo XIX. De la lectura de los artículos publicados en el Brasil de ese período, vamos a tratar de entender cómo los viajeros franceses vieron a los portugueses, el principal objeto de análisis es la relación entre el clima y la formación de las personas, elemento explicativo importante dentro de los conceptos del siglo XIX.

Palabras clave: Colonización portuguesa. Diálogos Transnacionales. Historia Cultural. Informes de los viajeros. Revue des Deux Mondes.

\section{Notas}

1 Poderíamos chegar até a Grécia Antiga, quando os gregos já demarcavam a Europa - e seu clima - como um ambiente ideal, em contraposição às demais zonas conhecidas, como fica claro no momento em que Aristóteles pregou o conceito de "zona tórrida", na qual, ao sul do Mediterrâneo, a temperatura era tão alta que a vida seria impossível; ou quando Heródoto também não via de maneira positiva os climas considerados mais quentes, tanto que preconizava: "países quentes, povos indolentes; países frios, povos robustos" (SANT'ANNA NETO, 1999, p. 48-50).

2 Àqueles interessados em conhecer melhor esse tema, consultar: Brasil, um país tropical: o clima na construção da identidade nacional brasileira (1839-1889) (2011), de Luis Fernando Tosta Barbato.

3 Prova disso é que podemos encontrar vestígios dessas teorias em importante autores do século XIX, como em Hegel ou Thomas Bluckle, além das questões referentes à discussão do "despotismo oriental" e do "modo de produção asiático", presentes em Marx e Engels (ARNOLD, 2000, p. 28-29). As palavras do importante naturalista britânico Alfred Russell Wallace deixam isso ainda mais claro: "¿No es un hecho que en todas las épocas y en cada rincón del globo, los habitantes de las regiones templadas han sido superiores a los de las regiones tropicales? Todas las grandes invasiones y todos los grandes desplaziamentos han sido de norte a sur, pero no al revés; y no tenemos registro de que alguna vez haya existido, como tanpoco hoy existe, un solo caso de civilización intertropical" (WALLACE apud ARNOLD, 2000, p. 32).

4 "Essa repugnância ao trabalho, essa despreocupação filosófica que os conquistadores sempre professaram em lugar do conforto, não podem ser atribuídas a uma falta de energia, pois nenhum povo que eu saiba manifestou maior quantidade de audácia e de atividades enérgicas que esta tribo celtibérica, confinada entre as montanhas e o oceano. Depois de haver repelido o islamismo, sentindo-se constrangida em sua língua materna, ela afrontou pela primeira vez os assustadores mistérios de um mar desconhecido e sem limites, explorou a costa da África, cruzou o Cabo das Tormentas, abriu a grande rota das Índias e povoou a Ásia com seus balcões; enquanto, por outro lado, Cabral, indo em direção ao oeste, reencontrou esse continente que Colombo procurou em vão. Foi também um português, 
Magalhães, que, desbravando os rigores do polo sul, entrou no Pacífico por uma nova rota e deu a seus companheiros a glória de percorrer em toda sua circunferência esse globo e este oceano, até então distantes da ciência e da investigação humana. De tais homens não se pode compreender o espírito inovador. Ouvi seu idioma tão rico, tão sonoro, tão apaixonado por cantar as façanhas dos heróis ou as cantigas dos santos: fica mudo quando vós pedis um tratado científico ou um livro de prática industrial. É uma língua de paladinos, não de artesãos. Tal língua, tal nação. Herdeiros do mundo romano e última personificação da Idade Média, esses homens munidos de espadas não viram no trabalho nada além da prerrogativa dos servos. Qualquer inovação que tocasse tal base deveria ser um crime. Â reforma, eles responderam pela inquisição. Enquanto as etnias anglo-saxãs abriram os ouvidos para a grande voz de Lutero, eles se colocaram sob a proteção de Dominique e Loyola. Os dois símbolos portaram seus frutos" (Tradução nossa).

5 "Entrez dans une ville de l'intérieur : vous y compterez les églises et les couvens par douzaines, et vous n'y trouverez pas une seule maison d'école. Les habitans sont obligés de recourir à Londres ou à New-York pour la plus petite machine, pour le plus mince tronçon de chemin de fer, et le fer se trouve en plusieurs endroits à fleur de terre et presque à l'état natif ! Enfin, chose impossible à croire, c'est quelquefois la Norvège qui alimente de bois de construction ce pays, le plus riche du monde en bois de toute sorte!" (D'ASSIER, 1863, p. 97). "Entre em uma cidade do interior: você vai contar as igrejas e conventos por dúzias, e você não vai encontrar uma única escola. Os habitantes são forçados a recorrer a Londres ou a Nova York pelo menor equipamento, pelo mais simples trilho de ferro, sendo que o ferro é encontrado em vários lugares ao nível do solo e quase no estado nativo! Enfim, algo impossível de se acreditar,é a Noruega, algumas vezes, que fornece madeira naquele país, o mais rico do mundo em madeiras de qualquer tipo!" (Tradução nossa).

6 Somente a partir de 1815, os franceses voltaram a pisar legalmente em solo brasileiro.

7 É, inclusive, considerado o responsável por uma "reconciliação com a ancestralidade lusitana e negra, de que todos nós nos vexávamos um pouco" (RIBEIRO, 1995, p. 109).

8 Vale lembrar que, nas décadas de 1920 e 1930, época em que Freyre publicou suas obras mais importantes, o pensamento social brasileiro ainda era marcado por teorias que derrubavam as esperanças de um futuro promissor para o Brasil. Teorias como o evolucionismo social, o positivismo, o naturalismo e o social-darwinismo, de origem europeia, que serviram como justificativa para a empreitada neocolonial de países como França e Inglaterra, pregavam a superioridade da raça branca - e, logo, a inferioridade das raças negras, indígenas e mestiças -, além de difamar o clima tropical, pregando supostos efeitos negativos sobre o corpo e a mente das pessoas (SCHWARCZ, 1993).

9 Sérgio Buarque de Holanda deixa claro que ambos os personagens metafóricos participam, em maior ou menor grau, de múltiplas combinações, inexistindo assim em estado puro. Portanto, "nem o aventureiro, nem o trabalhador possuem existência real fora do mundo das ideias" (HOLANDA, 1984, p. 14).

10 "Os camponeses caucasianos estabelecidos em Cuba e em Porto Rico, os ilhéus, que trabalham na terra nas Antilhas e em diversas partes do continente americano, provam, de uma maneira incontestável, por seu exemplo de uma prosperidade relativa, que certos brancos podem também, assim como os negros, cultivar o solo de terras tropicais; mas esses brancos aclimatados são originários da Espanha, de Portugal, da Madeira, dos Açores, das Canárias, e o sol forte de seu país natal já os tinha preparado para a temperatura da zona tórrida. Provavelmente os colonos vindos da Alemanha, da Irlanda e de outras terras do norte da Eupora poderiam também, sem perigo para sua saúde, aplicar-se à agricultura no Brasil equatorial e nas Guianas, sob a condição de manter rigorosa sobriedade, de mudar completamente seu modo de vida e de tomar precauções às quais jamais foram acostumados; mas não se poderia pedir um profundo conhecimento de higiene aos homens em miséria, exilados de sua terra natal, e que, pouco tempo antes de sua partida, ainda não saberiam se deveriam escolher como sua nova casa as margens geladas do Saint Laurent ou as florestas úmidas da Amazônia" (Tradução nossa).

11 "Os portugueses e os brasileiros são pessoas espirituais, mas pouco instruídas e desocupadas, pela intriga, eles exercem seu espírito e ficam sujeitos à mudança de sua ociosidade" (Tradução nossa).

12 "As causas remontam mais acima: elas têm sua origem nesse duro gênio português, misturado de fatalismo árabe e aspereza ibérica própria da epopeia, mas rebelde à ciência e ao trabalho. Desde que a primeira febre de ocupação se acalmou, os colonizadores não sonharam mais senão em 
gozar em paz da terra prometida. Seus descendentes iriam mais longe: deixando o elmo de seus rudes ancestrais pelo sombreiro do plantador e sua leal espada pelo chicote do feitor, eles se enrolaram em seu manto de fidalgos e deixaram às tribos vencidas o cuidado de lhes enriquecer. Menosprezando as lentas produções da terra, no entanto, tão fecundas sob os trópicos, eles não queriam nada além de ouro. Para dali extrair algumas barras, eles incendiaram florestas, perturbaram o solo, exterminaram os povos indígenas e condenaram à escravidão muitos milhões de negros" (Tradução nossa).

13 "Eles não foram sempre agressores (como no caso dos espanhóis) nas guerras com os indígenas, e eles não teriam feito mais que civilizá-los. Martim Afonso de Souza, Mem de Sá, Albuquerque, Coutinho, são homens cujos nomes chegaram com honra até nós" (Tradução nossa).

14 "No entanto, nessas miseráveis cabanas, o luxo da civilização se retirou ao mesmo tempo em que a religião" (Tradução nossa).

15 "O Brasil celebrou em 7 de setembro de 1872, o $50^{\circ}$ aniversário de sua independência. A dinastia, haste da antiga casa de Bragança, lançou no solo brasileiro raízes profundas. A constituição, fundada sobre a soberania e a representação nacional, funciona de uma maneira regular. As câmaras discutem livremente, os partidos, que além de tudo são fiéis às instituições e à dinastia, agitam-se com animação, às vezes com persistência, mas sem jamais sair dos limites da legalidade. Essa estabilidade política é a principal causa do progresso do Brasil. Esse imenso país, que representa sozinho mais de $2 / 5$ do continente da América do Sul, reserva riquezas naturais cuja exploração está apenas numa fase inicial" (Tradução nossa).

16 "A inteligente atividade dos mulatos deveria provocar a imitação da sociedade de origem portuguesa e europeia. Não é o caso. Essa sociedade vê a superioridade moral escapar-lhe sem tentar qualquer esforço para recuperá-la" (Tradução nossa).

\section{Referências}

ARNOLD, David. La naturaleza como problema histórico: el medio, la cultura y la expansíon de Europa. México: Fondo de Cultura Económica, 2000.
BARBATO, Luis Fernando Tosta. A invenção dos trópicos: clima e dominação à luz do Orientalismo de Edward Said. Temporalidades, Minas Gerais, v. 6, p. 52-64, 2014.

Brasil, um país tropical: o clima na construção da identidade nacional brasileira (1839-1889). Campinas: [s.n.], 2011.

. Da casa-grande ao mucambo: Gilberto Freyre e as origens do caráter nacional brasileiro. Revista de História, São Paulo, v. 2, n. 1, p. 32-48, 2010.

Entre preconceitos, conceitos e impressões: o Brasil e sua condição tropical na Revue des Deux Mondes (1829-1977). Campinas: [s.n.], 2015.

CHAVAGNES, Marie Louis de. Le Brésil em 1844: situation morale, politique, commerciale et financière. Revue des Deux Mondes, Paris, v. 15, n. 1 , p. 15-45. 1844.

D’ASSIER, Adolphe. Le Brésil et la société brésilienne. La fazenda? Revue des Deux Mondes, Paris, v. 34, n. 2, p. 18-20, 1863.

DECCA, Edgar Salvadori de. Cidadão, mostre-me a identidade! Caderno Cedes, Campinas, v. 22, n. 58, p. 45-56, 2002.

FREYRE, Gilberto. O mundo que o português criou: aspectos das relações sociais e de cultura do Brasil com Portugal e as colônias portuguesas. Rio de Janeiro: José Olympio, 1940.

GLACKEN, Clarance. Traces on the Rhodian Shore: nature and culture western thought from Ancient Times to the end of the eighteenth century. Berkeley: University of California Press, 1967.

GUIMARÃES, Manoel Luís Salgado. Nação e civilização nos trópicos: o Instituto Histórico e Geográfico Brasileiro e o projeto de uma história nacional. Estudos históricos, Rio de Janeiro, v. 1, n. 1, p. 5-17, 1988.

HOLANDA, Sérgio Buarque de. Raízes do Brasil. Rio de Janeiro: José Olympio, 1984. 
KEULLER, Adriana T. A. Martins. Retrato do Brasil: uma análise da tristeza pradiana. In: COSTA, Ricardo; PEREIRA, Valter Pires. (Orgs.). História: Revista do Departamento de História da UFES. Vitória: EDUFES, 2001.

LACORDAIRE, Théodore. L'or de Pinheiros. Revue des Deux Mondes, Paris, v. 5, n. 1, p. 6-18, 1863.

MONTEIRO, Pedro Meira. A queda do aventureiro: aventura, cordialidade e os novos tempos. In: HOLANDA, Sérgio Buarque de. Raízes do Brasil. Campinas: Editora da Unicamp, 1999.

RECLUS, Elisée. Le Brésil et la colonisation - le bassin des Amazones et les indiens. Revue des Deux Mondes, Paris, v. 11, n. 1, p. 67-75, 1862.

RIBEIRO, Darcy. O povo brasileiro: a formação e o sentido do Brasil. São Paulo: Cia. das Letras, 1995.

SAINT-ARMAND, Imbert. Le Brésil et les republiques de la Plata aprés la guerre du Paraguay. Revue des Deux Mondes, Paris, v. 44, n. 2, p. 15-26, 1873.

SAINT-HILAIRE, Auguste de. Tableau de dernières révolutions du Brésil. Revue des Deux Mondes, Paris, v. 2 , n. 2, p. 55-63.

SANT'ANNA NETO, João Lima. História da climatologia no Brasil: gênese e paradigmas do clima como fenômeno geográfico. Cadernos Geográficos (Universidade Federal de Santa Catarina), Florianópolis, n. 1, p. 23-37, 1999.

SCHWARCZ, Lilia Moritz. O espetáculo das raças: cientistas, instituições e questão racial no Brasil - 1870-1930. São Paulo: Companhia das Letras, 1993.

VENTURA, Roberto. Estilo Tropical: História Cultural e polêmicas literárias no Brasil - 18701914. São Paulo: Cia. das Letras, 1991. 